\title{
COM INTEGRAR UN FOCUS EN LA GRAMÀTICA A LES CLASSES COMUNICATIVES DE LLENGUA*
}

\author{
HOW TO INTEGRATE A FOCUS ON GRAMMAR \\ INTO COMMUNICATIVE LANGUAGE CLASSROOMS
}

\author{
Hossein Nassaji \\ University of Victoria, Victoria (Canadà) \\ nassaji@uvic.ca
}

Resum: Hi ha un ampli suport teòric i empíric en el camp de l'adquisició de segones llengües (L2) per a les estratègies d'instrucció que dirigeixen l'atenció de l'aprenent cap a les formes gramaticals durant les activitats centrades en el significat. Aquest tipus d'instrucció s'ha anomenat «instrucció de focus en la forma» i s'ha distingit dels enfocaments tradicionals basats en la gramàtica que ensenyen formes lingüístiques de manera aïllada i descontextualitzada, que s'ha anomenat «instrucció de focus en les formes». Aquest article comença amb una breu descripció de la noció de focus en la forma i els seus fonaments teòrics i empírics. A continuació, es presenten una sèrie d'opcions d'instrucció per a la integració d'un enfocament en la gramàtica en l'ensenyament comunicatiu de llengües. Es descriu cada opció, se'n repassen les bases teòriques i empíriques i es donen exemples de com es poden utilitzar a l'aula.

Paraules clau: focus en la forma, ensenyament de la gramàtica, enfocament comunicatiu, instrucció a l'aula.

Abstract: There is ample theoretical and empirical support in the field of second language (L2) acquisition for instructional strategies that direct learners' attention to grammatical forms during meaning-focused activities. This kind of instruction has been referred to as «focus on form instruction", and has been distinguished from the traditional grammar-based approaches that teach linguistic forms in an isolated and decontextualized manner, or what has been called «focus on forms instruction». In this article, I will begin with a brief overview of the notion of

$\left.{ }^{*}\right)$ Traducció de l'anglès al català de Núria Camps. Adaptació de Llorenç Comajoan-Colomé. 
Hossein NASSAjI

Com integrar un focus en la gramàtica a les classes comunicatives de llengua

focus on form and its theoretical and empirical underpinnings. I will then discuss a number of instructional options for integrating a focus on grammar into communicative language teaching. I will describe each option, review its theoretical and empirical basis, and provide examples of how they can be used in the classroom.

Key words: focus on form, grammar teaching, communicative approach, language instruction.

\section{$\cos \cos$}

\section{INTRODUCCIÓ}

La insatisfacció amb els enfocaments tradicionals centrats en la gramàtica, d'una banda, i les inadequacions dels enfocaments d'ensenyament de llengua basats únicament en el significat que obvien les formes gramaticals, de l'altra, han portat molts investigadors de segones llengües (L2) a proposar que, per ser eficaç, l'atenció a les formes lingüístiques ha de tenir lloc en el context de la comunicació centrada en el significat (Doughty \& Williams 1998b; Ellis 200I; Fotos \& Nassaji 2007; Long 199I; Long \& Robinson I998; Nassaji 20I5, 2016a; Nassaji \& Fotos 2007, 2010; Nassaji \& Simard 20I0; Williams 2005). Aquest tipus d'ensenyament ha estat anomenat focus on form [focus en la forma] i s'ha contrastat amb els enfocaments tradicionals centrats en la forma, en els quals se seleccionen determinades formes gramaticals i s'ensenyen de manera aillada i no comunicativa (Long \& Robinson 1998). ${ }^{1}$ El supòsit que hi ha darrere la perspectiva del focus en la forma és que l'aprenentatge té lloc de manera més efectiva quan se centra l'atenció de l'alumnat sobre les formes gramaticals mentre el focus principal de l'aprenent rau en el processament del significat. Altres dues característiques principals d'aquest enfocament són: $a$ ) hi ha un breu canvi d'enfocament del focus en la comunicació al focus en les formes lingüístiques i $b$ ) hi ha un problema comunicatiu d'algun tipus que ha desencadenat el focus en la forma. En aquest article, començo amb un breu panorama sobre la noció de focus en la forma i els seus fonaments teòrics i empírics. A continuació, plantejo diverses opcions d'ensenyament

I. Per a discussions sobrel'ensenyament de la gramàtica en els contextos catalanoparlant i castellanoparlant, vegeu, entre d'altres, Camps (2005), Camps \& Ferrer (2000), Castañeda (20I4), Comajoan (20I4a, 20I4b), Consorci per a la Normalització Lingüística (2015), Cuenca (2005), Ribas, Fontich \& Guasch (2014), Rodríguez Gonzalo \& García Folgado (2014) i Llopis-García et al. (20I2). Aquest article se centra principalment en l'ensenyament-aprenenentatge de segones llengües (sobretot l'anglès) per part d'adults. Per a una discussió sobre les diferències en la recerca en gramàtica amb adults i infants-joves a Catalunya, vegeu Comajoan (20I4b). 
d'L2 per a la integració d'un focus en la gramàtica en l'ensenyament comunicatiu de llengües. Finalment, descric cada opció, en reviso els fonaments teòrics i empírics, i dono exemples de com es poden utilitzar a l'aula.

\section{FOCUS EN LA FORMA}

El focus en la forma és un tipus d'ensenyament que extreu els seus principis d'un enfocament comunicatiu, però al mateix temps sosté que els aprenents necessiten prestar atenció a les formes lingüístiques per tal d'aprendre-les amb èxit. Aquesta perspectiva s'aplica tant als infants com als adults que aprenen una L2 i defensa que l'atenció a la forma s'integri en un context en el qual el focus principal sigui la comunicació.

L'enfocament del focus en la forma (FonF, segons la seva denominació abreujada en anglès) va ser proposat originalment per Long (199I) en resposta als problemes presentats pels enfocaments tradicionals d'ensenyament de llengües (que ell va anomenar focus on forms [focus en les formes]). En concret, Long distingeix entre tres tipus d'instrucció: el focus en les formes, el focus en el significat i el focus en la forma (Long I99I; Long \& Robinson 1998).

El focus en les formes implica ensenyar gramàtica d'una manera altament descontextualitzada. Parteix d'un currículum sintètic i es basa en el supòsit que el llenguatge consisteix en una sèrie de formes gramaticals que es poden adquirir de forma seqüencial i additiva. En aquest enfocament, les formes lingüístiques són preseleccionades i el docent intenta centrar l'atenció dels aprenents cap a aquestes formes de manera aillada sense gaire preocupació pel significat i la comunicació. Aquest enfocament és problemàtic perquè, tot $\mathrm{i}$ que pot ajudar els aprenents a desenvolupar el coneixement declaratiu (és a dir, el coneixement sobre la llengua), no els ajuda a desenvolupar de manera adequada el coneixement comunicatiu (és a dir, la capacitat d'utilitzar el llenguatge de forma espontània en contextos comunicatius). Hi ha evidències procedents tant de l'experiència d'estudiants d'L2 com de la recerca sobre ASL (adquisició de segones llengües) sobre el fet que les activitats descontextualitzades, com ara repeticions, omplir buits, exercicis de transformació i altres activitats similars que presenten regles gramaticals de manera discreta sense referència al significat, poden promoure el coneixement sobre el llenguatge, però no necessàriament promoure'n l'adquisició il'ús.

El focus en el significat emfatitza les activitats purament basades en el significat sense prestar atenció a la forma. Aquest enfocament es basa en un currículum analític i en el supòsit que els aprenents són capaços d'analitzar el llenguatge de forma inductiva i arribar a la gramàtica subjacent de la llengua. Aquest enfocament també s'ha

Caplletra 63 (Tardor, 2017), pp. 165-188 
Hossein NASSAjI

Com integrar un focus en la gramàtica a les classes comunicatives de llengua

considerat inadequat. Una font important d'evidències que mostren les limitacions d'aquest enfocament prové d'estudis que han analitzat el desenvolupament de la competència lingüística dels programes d'immersió basats en continguts en joves aprenents d'L2. Els resultats van demostrar que els enfocaments purament comunicatius o centrats en el significat, sense focus en la gramàtica o correcció d'errors, eren insuficients per ajudar els aprenents a millorar en correcció en molts aspectes de l'L2 (vegeu l'apartat 3).

El focus en la forma és un enfocament que intenta abordar les limitacions dels dos enfocaments anteriors, centrant l'atenció de l'alumnat cap a les formes lingüístiques en el context d'una comunicació significativa. En l'actualitat hi ha un consens creixent entre els investigadors d'L2 sobre el fet que un enfocament com aquest és més eficaç que el que se centra només en el significat o exclusivament en les formes lingüístiques. La importància de la perspectiva del focus en la forma es basa en una sèrie de suposicions sobre com s'aprèn una llengua. Una d'elles és que la llengua no es pot aprendre sense un cert grau de consciència. Una altra hipòtesi és que la cognició humana té una capacitat limitada. Per tant, els aprenents no poden prestar atenció a la forma i al significat de forma simultània durant la comunicació (VanPatten 1996, 2002). Finalment, s'assumeix que l'atenció a la forma és més eficaç quan es proporciona en un context en el qual el focus principal és en el significat. El focus en la forma també té beneficis perquè proporciona un suport cognitiu en un doble sentit: tant pel context general de significat com pel fet que l'atenció a la forma té lloc en el moment en el qual els aprenents la necessiten per a la comunicació. Per exemple, Doughty \& Varela (1998: II4) van suggerir que les estratègies de focus en la forma són eficaces, ja que el seu objectiu és «afegir atenció a la forma en una tasca fonamentalment comunicativa, més que no pas desviar-se d'un objectiu que ja és comunicatiu per discutir un aspecte lingüístic». Long (2000) va assenyalar que, atès que el focus en la forma es produeix durant activitats comunicatives, té lloc quan l'aprenent té un problema de comunicació i, per tant, està centrat en l'alumne i concorda amb el procés de desenvolupament i adquisició de l'aprenent.

Long (199I) va concebre originalment el FonF sobretot com un tipus d'atenció incidental a la forma induïda de manera reactiva en resposta als problemes gramaticals. Altres investigadors, però, han ofert una perspectiva més àmplia del focus en la forma, amb l'argument que es pot proporcionar de diferents maneres $i$, per tant, no s'ha de limitar a les reaccions incidentals dels problemes dels aprenents. Doughty \& Williams (1998a), per exemple, van suggerir que el focus en la forma es pot aconseguir tant de forma reactiva (per exemple, en resposta als errors dels aprenents durant la comunicació) 
com de manera proactiva (per exemple, a través del tractament de formes lingüístiques específiques de manera predeterminada). El focus en la forma també pot tenir lloc tant de manera integrada com seqüencial (Lightbown 1998). L'opció seqüencial té lloc quan l'ensenyament de la gramàtica es produeix en minilliçons separades seguides o precedides d'activitats comunicatives. Aquest enfocament és especialment important en contextos de llengua estrangera en els quals l'accés a la llengua meta és limitat. En canvi, el focus en la forma integrat té lloc en el context de la comunicació, per mitjà d'estratègies com ara la correcció d'errors o side sequences [seqüències laterals] integrades en els fluxos de comunicació per ajudar els aprenents amb els problemes que puguin tenir durant la comunicació. El focus en la forma també es pot aconseguir de manera preventiva (Ellis 200I) utilitzant part del temps destinat a una activitat comunicativa per centrar-se breument en una forma concreta que es preveu que serà problemàtica. L'opció preventiva és una estratègia incidental i és particularment útil per abordar les formes lingüístiques que es produeixen de forma espontània en el transcurs d'una activitat centrada en el significat. Tenint en compte les diverses opcions per al focus en la forma, Nassaji \& Fotos (2010: 13) van oferir la següent concepció del FonF:

[FonF fa referència a] una sèrie d'opcions metodològiques que, tot i que s'adhereixen als principis de l'ensenyament comunicatiu de llengües, intenten mantenir un focus en les formes lingüístiques de diverses maneres. Un focus com aquest es pot aconseguir de manera explícita i implícita, deductivament o inductivament, amb o sense una planificació prèvia, i integrativament o seqüencialment. També creiem que el FonF ha de ser un component d'un aprenentatge instruït de l'L2 més ampli que ha d'oferir suficients oportunitats per a un ensenyament significatiu i centrat en la forma i també una gamma d'oportunitats per a l'input d'L2, l'output, la interacció i la pràctica.

En poques paraules, des de la perspectiva del focus en la forma, l'èxit de l'ensenyament de la gramàtica depèn de fins a quin punt es proporciona aquest ensenyament en un context en el qual el focus general se centra en la comunicació. Tenint en compte això, per tant, l'objectiu de l'ensenyament de la gramàtica hauria de ser ajudar els aprenents a desenvolupar l'habilitat d'expressar el significat de manera efectiva i correcta en comptes de mostrar simplement els seus coneixements de la llengua meta. Aquest tipus d'ensenyament de la gramàtica es considera beneficiós, perquè, quan els aprenents posen l'atenció sobre la forma en el context de la comunicació, és possible que no només vegin la forma en la seva producció, sinó que també en reconeguin el valor comunicatiu. 
Hossein NASSAjI

Com integrar un focus en la gramàtica a les classes comunicatives de llengua

\section{EVIDĖNCIES EMPÍRIQUES DEL FOCUS EN LA FORMA}

Una línia important de suport de la importància del focus en la forma a les aules d'L2 prové d'estudis que han examinat el desenvolupament de la competència lingüística quan s'aprèn la llengua en aules basades en continguts o en aules d'immersió. Segons les evidències d'aquest tipus de recerca, l'ensenyament centrat principalment en el significat i en el qual no hi ha instrucció gramatical ni correcció d'errors és inadequat per fer que els aprenents assoleixin la correcció en molts aspectes de l'L2. Per exemple, com s'ha assenyalat anteriorment, una àmplia investigació sobre els resultats de l'aprenentatge en els programes d'immersió en francès al Canadà amb aprenents joves d'L2 va demostrar que, malgrat una exposició substancial a input significatiu a llarg termini, els aprenents no assolien la correcció en certes formes gramaticals (Harley \& Swain 1984; Lapkin, Hart \& Swain 1991; Swain 1985; Swain \& Lapkin 1989). Aquests estudis suggereixen que és necessari algun tipus de focus en la forma en contextos comunicatius si es vol que els aprenents desenvolupin nivells alts de correcció en la llengua meta.

També hi ha evidències a partir d'un extens cos de recerca dels últims 40 anys (tant amb infants com amb adults, així com també amb aprenents de nivell principiant, intermedi i avançat) que l'ensenyament de gramàtica té efectes positius en l'aprenentatge de l'L2 en comparació amb altres enfocaments (vegeu Loewen 2015 i Nassaji 20I6b per a una cronologia dels estudis). Per exemple, els estudis dels efectes de la instrucció en el desenvolupament de formes específiques de la llengua meta (Cardierno 1995; Lightbown 1992; Lightbown \& Spada 1990) i els estudis de l'efecte del feedback correctiu en els errors de l'aprenent (Carroll \& Swain 1993; Leeman 2003; Lyster 2004; Lyster \& Ranta 1997; Mackey \& Philp 1998; Nassaji 2007, 2009, 2015, 20I6a; Oliver 1995) indiquen que la instrucció gramatical té un efecte significatiu en l'assoliment de la correcció, especialment si es proporciona quan l'atenció de l'alumnat se centra en el significat (Ellis 2006; Lightbown \& Spada 1990; Norris \& Ortega 2000, 200I). En aquest sentit, Lightbown \& Spada (1990) van examinar el paper que jugava el focus en la forma en l'aprenentatge de l'anglès per part de parlants nadius de francès en programes d'anglès com a L2 en els quals el mètode d'ensenyament de la llengua era principalment comunicatiu i centrat en el significat. Es va analitzar una àmplia base de dades d'observació d'aula amb el focus en l'ús, per part dels aprenents, de característiques gramaticals com have, be, -s de plural, -ing progressiu, col-locació de l'adjectiu en frases nominals i ús de determinants possessius. Els resultats van indicar que els aprenents d'aules on hi havia més ensenyament centrat en la forma i feedback correctiu eren més precisos en l'ús de formes gramaticals, com ara en l'ús del morfema 
-ing progressiu i les col-locacions substantiu-adjectiu, que no pas els d'aules en què havien rebut una menor instrucció centrada en la forma i feedback correctiu oral durant la interacció oral. Altres estudis que han examinat el paper de la instrucció centrada en la forma en classes comunicatives també han mostrat resultats similars. Revisant aquesta línia d'investigació, Lightbown \& Spada (I993: I05) van concloure el següent:

Les dades provinents d'aules de molts estudis donen suport a la perspectiva que la instrucció centrada en la forma i el feedback correctiu ofert en el marc d'un programa comunicatiu són més eficaços en la promoció de l'aprenentatge d'una segona llengua que els programes que es limiten a posar èmfasi exclusivament en la correcció, d'una banda, o èmfasi exclusiu en la fluïdesa, de l'altra.

Des de Lightbown \& Spada (I993) s'han realitzat molts altres estudis centrats en la forma, que han demostrat que l'efecte de la instrucció és complex i que pot variar depenent de diversos factors, que inclouen, per exemple, el nivell d'interllengua dels aprenents, la complexitat de la relació entre la forma i la funció, la relació entre l'Li i l'L2, i altres diferències individuals dels aprenents (vegeu Loewen 20I5 i Nassaji 20I6b per a una revisió dels estudis més recents). En resum, els estudis confirmen que la instrucció exitosa requereix àmplies oportunitats tant de focus en la forma com de focus en el significat.

\section{TIPUS DE FOCUS EN LA FORMA}

El focus en la forma es pot integrar en un context comunicatiu de diferents maneres. Les diferents estratègies per fer-ho difereixen entre elles en aspectes importants com ara el grau d'explicitació, el tipus d'ensenyament, la temporització, la intenció del professorat o dels aprenents i el grau de planificació. Utilitzant aquests criteris, els investigadors en ASL han elaborat diverses classificacions (Doughty 200I; Doughty \& Williams I998a; Ellis 200I; Long 199I; Long \& Robinson 1998; Nassaji 20I5; Nassaji \& Fotos 20I0; Nassaji \& Simard 20I0; Williams 2005). Nassaji \& Fotos (2010) van utilitzar diverses modalitats d'ensenyament i van dividir el focus en la forma en quatre tipus segons si era basat en l'input, en l'output, en la interacció o en la tasca (figura I). Cada tipus es pot dividir alhora en diversos subtipus. Per exemple, els subtipus de focus en la forma basats en l'input poden ser la instrucció de processament, la millora textual i l'input flood [inundació d'input]. El focus en la forma pot integrar-se en tasques centrades en el significat de dues maneres: a través del disseny (és a dir, mitjançant el desenvolupament de tasques amb un focus específic en la llengua) o

Caplletra 63 (Tardor, 2017), pp. 165-188 
mitjançant el procés (és a dir, mitjançant la realització d'activitats pretasca i posttasca que aborden els trets lingüístics necessaris per realitzar la tasca) (Nassaji 1999). Les formes lingüístiques també es poden abordar mentre els estudiants estan duent a terme la tasca si se'ls proporciona feedback sobre la seva producció. A continuació, es valora breument cada tipus amb les seves subestratègies i es proporcionen exemples i evidències d'investigació per determinar-ne l'efectivitat.

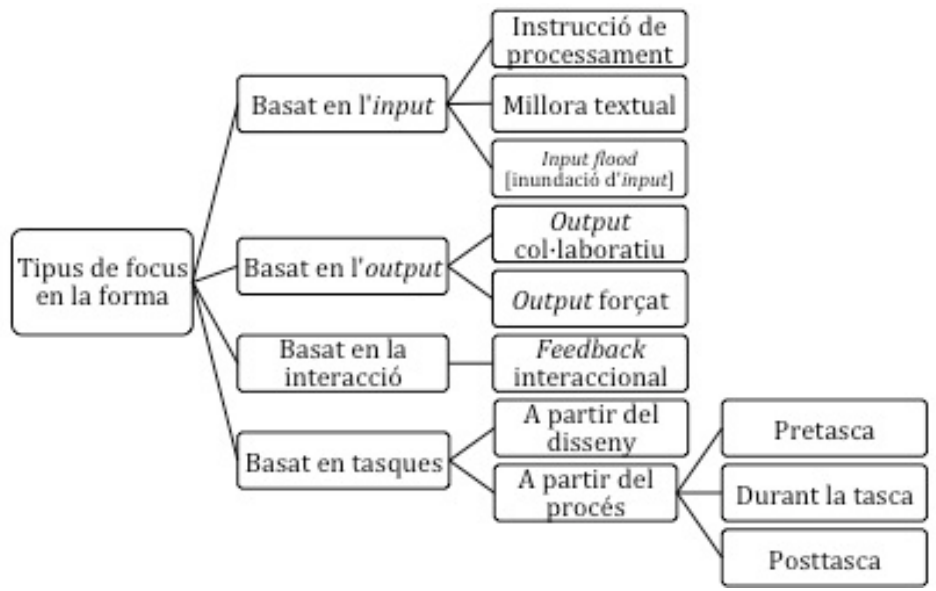

Figura r: Tipus de focus en la forma.

\section{I. FOCUS EN LA FORMA BASAT EN L'INPUT}

El focus en la forma basat en l'input fa referència a les estratègies d'ensenyament que impliquen l'ús d'input mentre els estudiants l'estan processant a la recerca de significat comunicatiu. Aquest enfocament es basa en la suposició que es pot centrar l'atenció dels aprenents sobre les formes gramaticals mitjançant activitats basades en l'input, la finalitat de les quals és entendre o processar l'input per a la comprensió. Alguns exemples podrien ser el processament d'input, diverses formes de millora textual (tant oral com escrita) i la inundació d'input. La instrucció de processament (IP) és un enfocament particular de l'ensenyament de la gramàtica que es basa en la manera com els aprenents processen l'input (VanPatten 2002, 2004). En aquest enfocament es combina una exposició inicial a l'ensenyament explícit amb un seguit d'activitats de processament d'input (anomenades input estructurat), que es creu que ajuden els 
aprenents a crear connexions entre significat i forma en l'input i, per tant, a "processar la gramàtica a la recerca de significat» (J. Lee \& VanPatten 1995). A causa del focus explícit en la forma d'aquest enfocament, alguns investigadors l'han equiparat amb el focus en les formes de Long (Sheen 2002). VanPatten (2002: 764), però, va argumentar que com que l'objectiu d'aquest enfocament és «ajudar l'aprenent en la realització de connexions entre forma i significat durant la IP, és més apropiat veure-ho com un tipus de focus en la forma».

Les activitats d'aula que s'utilitzen en el processament d'inputs'anomenen input estructurat: s'anomenen així perquè es dissenyen específicament per tal que continguin input que ajudi els aprenents a connectar forma i significat. Per exemple, l'activitat següent (basada en les publicacions de VanPatten i els seus col-laboradors) és un exemple d'activitat d'input estructurat. ${ }^{2}$ L'objectiu és empènyer l'alumnat a processar el marcador morfològic de l'anglès -ed que, d'altra manera, poden no detectar si se'ls proporciona un adverbi de passat.

Enunciat per als alumnes: Escolta les frases següents $i$ decideix si descriuen una acció anterior o una acció que se sol fer habitualment (Nassaji \& Fotos 20IO).

I. The teacher corrected the essays. [El professor va corregir les redaccions.]

Ara Abans

2. The man cleaned the table. [L'home va desparar la taula.]

3. I wake up at 5 in the morning. [Em desperto a les 5 del matí.]

4. The train leaves the station at $8 \mathrm{am}$. [El tren surt de l'estació a les 8 del matí.]

5. The writer finished writing the book. [L'escriptor va acabar d'escriure el llibre.]

6. The trees go green in the spring. [Els arbres es tornen verds a la primavera.]

Molts estudis han comparat l'eficàcia de la IP amb la de l'ensenyament tradicional amb un focus en la pràctica de l'output (Allen 2000; Benati 200I; Benati \& Lee 2008; Cardierno I995; Cheng 2002; Lee \& Benati 2013; MorganShort \& Bowden 2006; VanPatten \& Cadierno I993; Wong 2004). En general, els resultats han mostrat evidències a favor de la IP, en particular quan s'utilitza en combinació amb la instrucció explícita. No obstant això, també han demostrat que

2. Per a exemples de materials didàctics en català com a L2 basats en processament de l'input, vegeu Comajoan (200I) i Bastons, Bernadó \& Comajoan (20II). Per al castellà com a L2, vegeu VanPatten, Leeser \& Keating (20II).

Caplletra 63 (Tardor, 2017), pp. 165-188 
Hossein NASSAjI

Com integrar un focus en la gramàtica a les classes comunicatives de llengua

l'efectivitat de la IP depèn d'una sèrie de factors, incloent-hi el tipus i la complexitat de l'estructura que s'aprèn i el tipus d'habilitat que es mesura. En la seva revisió dels estudis d'IP, Dekeyser \& Botana (20I4) (vegeu també Dekeyser \& Sokalski 200I), per exemple, van arribar a la conclusió que la IP podria ser més efectiva per promoure les habilitats de comprensió, mentre que la instrucció basada en la producció podria ser més efectiva per promoure les habilitats de producció. També van observar que els resultats dels estudis que comparen la IP amb la instrucció basada en l'output depenien de com es posava en pràctica la instrucció a l'aula.

Les tècniques de millora textual tenen com a objectiu centrar l'atenció de l'alumnat sobre la forma a partir de la posada en relleu de certs aspectes de l'input mitjançant recursos tipogràfics en l'input escrit (negreta, subratllat i cursiva) o recursos acústics en l'input oral (èmfasi o repeticions). D'altra banda, la inundació d'input consisteix a proporcionar molts exemples de la mateixa forma lingüística a l'input (vegeu Nassaji \& Fotos 2010 per exemples d'activitats de classe). El supòsit darrere d'aquestes dues tècniques és que la millora tipogràfica d'elements lingüístics o el seu ús freqüent a l'input pot augmentar la seva prominència $i$, per tant, pot promoure la detecció de les formes (Schmidt 1990, 2010; Sharwood Smith 1993).

Els estudis que han examinat l'efectivitat de la millora textual i de la inundació d'input han ofert resultats diferents (vegeu Lee $\&$ Huang 2008 per una metaanàlisi). Mentre que la majoria d'estudis ha demostrat un efecte positiu de la millora textual en la detecció de les formes lingüístiques, si parem atenció a l'aprenentatge, els resultats no són tan prometedors. Això no és sorprenent, ja que la millora textual i la inundació d'input simplement proporcionen als estudiants els models correctes de llengua o el que es coneix com a evidència positiva. En canvi, no proporcionen als aprenents informació sobre el que és incorrecte en una llengua determinada (evidència negativa).

\subsection{FOCUS EN LA FORMA BASAT EN L'OUTPUT}

El focus en la forma basat en l'output fa referència a l'ensenyament gramatical de l'L2 que intenta ajudar els estudiants a aprendre les formes gramaticals centrant la seva atenció en les estructures gramaticals quan s'eliciten per mitjà de l'output. Tal com s'ha mencionat anteriorment, Swain i els seus col-legues van demostrar que, malgrat molts anys d'experiència i exposició a l'input significatiu, els aprenents d'immersió en francès al Canadà tenien greus problemes amb certes formes gramaticals. Swain (1985, 1995) va argumentar que aquest problema estava relacionat, en part, amb el fet 
que els estudiants no estaven obligats a produir output o, si ho estaven, els docents no els empenyien prou per anar més enllà del nivell d'interllengua que tenien en aquell moment. Per això, va proposar que els aprenents havien de produir output, ja que la producció juga un paper important en el desenvolupament d'una segona llengua. Amb aquesta finalitat, Swain (1985, 1995) va suggerir tres funcions principals de l'output: la de detecció, la de comprovació d'hipòtesis i la metalingüística.

La funció de detecció de l'output fa referència al fet que quan els aprenents produeixen output, s'adonen que no són capaços de dir el que voldrien dir. En altres paraules, l'output ajuda els aprenents a detectar un buit en el seu coneixement de la interllengua. La funció de comprovació d'hipòtesis fa referència al fet que quan els aprenents diuen o escriuen alguna cosa s'impliquen en la formulació i comprovació de la seva pròpia hipòtesi sobre com funciona el llenguatge. En aquest sentit, també poden rebre feedback del seu interlocutor, que després pot ajudar-los a modificar o revisar les seves hipòtesis. En el cas de la funció metalingüística, quan els aprenents produeixen output, adquireixen control sobre els seus coneixements lingüístics i els interioritzen. D'aquesta manera, l'output també permet un processament sintàctic més profund, ja que ajuda els aprenents a «avançar des del processament semàntic, estratègic i obert que preval en la comprensió cap a un processament gramatical complet necessari per a la producció acurada» (Swain 2000: 99).

Per les raons que s'acaben de mencionar, és important utilitzar tasques a l'aula que promoguin l'output. Alguns exemples de tasques d'output que poden ser útils per als aprenents inclouen diversos tipus d'activitats d'output forçat (pushed output) o activitats col-laboratives d'output. En les activitats d'output col-laboratiu, per exemple, els aprenents s'involucren activament en el procés d'aprenentatge i també descobreixen els seus punts forts i febles mitjançant la descoberta del que saben i del que no saben de la llengua. L’objectiu de l'output colllaboratiu no és només centrar l'atenció dels aprenents en certes formes gramaticals, sinó també promoure la negociació de forma i significat. Aquestes activitats són beneficioses per als estudiants d'L2, perquè quan l'output es produeix col-laborativament, els aprenents no només són empesos a utilitzar l'estructura meta, sinó que també comptaran amb l'ajuda dels seus companys quan es tracti d'oferir un significat precís (Kowal \& Swain 1994; Swain \& Lapkin 200I).

Hi ha una gran varietat de tasques d'output colllaboratiu per a les aules d'L2 que promouen la discussió sobre les formes lingüístiques. Una de les tasques que ha rebut molta atenció en la recerca és el dictogloss (Wajnryb 1990). Un dictogloss és un tipus de tasca d'output col-laboratiu que encoratja els aprenents a treballar conjuntament per reconstruir un text després que se'ls hagi presentat de manera oral. En 
Hossein NASSAjI

Com integrar un focus en la gramàtica a les classes comunicatives de llengua

aquesta activitat, el docent normalment llegeix un text breu dues vegades i demana als aprenents que treballin en grups per reproduir el text tan semblant com sigui possible al text original. Diversos estudis han investigat l'ús i l'eficàcia del dictogloss $\mathrm{i}$ han demostrat efectes positius d'aquesta tasca en la promoció de l'atenció cap a la forma i el desenvolupament de l'L2. Kowal \& Swain (1994), per exemple, van mostrar que quan els aprenents treballaven junts per reconstruir un text, s'adonaven de buits en els seus coneixements lingüístics, es fixaven en la relació entre forma i significat i rebien feedback dels seus companys. Swain \& Lapkin (200I) van notar que l'ús del dictogloss portava a una reproducció més precisa de les formes de la llengua meta, en comparació amb altres tasques, com ara les tasques de jigsaw (trencaclosques) (vegeu també Nabei 1996). Nassaji \& Tian (2010) van avaluar l'eficàcia de les tasques de reconstrucció de l'output quan es duien a terme col-laborativament i de forma individual i van mostrar que quan els aprenents completaven aquestes tasques colllaborativament, la correcció de la tasca augmentava significativament. En resum, els estudis sobre l'output col-laboratiu han demostrat efectes beneficiosos per a aquestes tasques pel que fa a les oportunitats de centrar l'atenció en la forma i en la interacció.

\subsection{FOCUS EN LA FORMA BASAT EN LA INTERACCIÓ}

El focus en la forma basat en la interacció fa referència a les opcions que centren l'atenció dels aprenents cap a les formes gramaticals mentre els aprenents estan involucrats en diverses formes de discussió a classe i d'interacció centrada en el significat. Una manera de fer-ho és a través de feedback interaccional, que fa referència a les diverses estratègies de negociació i modificació que s'utilitzen per centrar l'atenció dels aprenents de manera implícita o explícita cap a les formes gramaticals. En teoria, aquest enfocament es basa en una perspectiva interaccionista del'adquisició de segones llengües i en el supòsit que la negociació de significat és essencial per a l'adquisició de llengües (Gass 2003; Long 1996; Pica 1994). S’ha proposat que, a través de la negociació, els aprenents no només comuniquen el seu significat, sinó que també reben feedback negatiu (és a dir, correctiu) sobre la seva producció a través d'estratègies com la repetició, la petició d'aclariments, les marques de confirmació, etc. (Gass 2003; Long 1996). Les estratègies de feedback posen en relleu els problemes lingüístics i empenyen l'aprenent a modificar interaccionalment la seva llengua i a produir enunciats que siguin més precisos i més comprensibles (Long 1996). 
El feedback correctiu es pot utilitzar en diversos contextos (a dins o fora de l'aula) i en interacció, és a dir, quan el docent o un interlocutor interactua, ja sigui amb infants $\mathrm{o}$ amb adults que aprenen una llengua. Per exemple, una d'aquestes estratègies (que també ha rebut molta atenció en la recerca en ASL) és el recast (reformulació). Aquest tipus de feedback fa referència a la reformulació correcta de l'expressió errònia de l'aprenent per part del docent durant la interacció comunicativa. Per exemple, en l'intercanvi que es mostra a continuació, el docent i l'aprenent estan interactuant i el docent planteja una pregunta (línia I). L'aprenent respon a la pregunta, però comet un error en la seva resposta (línia 2). El docent, llavors, reformula la resposta de l'aprenent tot corregint l'error (línia 3). Finalment, l'aprenent respon corregint el seu error original (línia 4).

$\begin{array}{ll}\text { I. Docent: } & \text { What can you see in this picture? [Què veus en aquesta foto?] } \\ \text { 2. Aprenent: } & \text { I see banana. [Veig plàtan.] } \\ \text { 3. Docent: } & \text { You see a banana? [Veus un plàtan?] } \rightarrow \text { [Reformulació] } \\ \text { 4. Aprenent: } & \text { A banana [Un plàtan] }\end{array}$

Actualment, hi ha molts estudis que han investigat el paper dels diversos tipus de feedback correctiu i interaccional per a l'aprenentatge de l'L2. Els resultats d'aquests estudis, que han estat resumits en una sèrie de revisions i metaanàlisis de recerca, han indicat que les reformulacions són beneficioses per al'adquisició de llengües en general (per exemple, Li 20IO; Lyster \& Saito 20IO; Mackey \& Goo 2007; Nassaji 20I5, 20I6a; Russell \& Spada 2006). ${ }^{3}$ Amb tot, $s$ han observat variacions significatives en els resultats d'aquests estudis. Per exemple, mentre que alguns han descobert un efecte significatiu de les reformulacions, altres han conclòs que no són gaire efectives en comparació amb altres tipus de feedback correctiu, com ara l'elicitació i el feedback metalingüístic. Aquestes diferències en els resultats de recerca no haurien de ser sorprenents, ja que el feedback interaccional és un fenomen complex i la seva eficàcia pot variar depenent de molts factors: a més del tipus de feedback, com ara l'objectiu lingüístic, el context de les reformulacions, el domini de l'idioma, el grau de desenvolupament dels aprenents i altres diferències individuals. Mackey \& Philp (1998), per exemple, van concloure que els aprenents amb un desenvolupament lingüístic més avançat es van beneficiar més de les reformulacions que aquells que tenien un desenvolupat menys avançat. Lyster (1998) va mostrar que tant el fet de fer o no reformulacions com la utilitat

3. Per a una introducció i discussió en català del concepte de reformulació en l'ensenyament de llengües, vegeu Lyster (2016).

Caplletra 63 (Tardor, 2017), pp. 165-188 
Hossein NASSAjI

Com integrar un focus en la gramàtica a les classes comunicatives de llengua

que tenien diferia depenent de la naturalesa de l'estructura meta (gramatical, lèxica i fonològica) i que, després de les reformulacions, els errors fonològics es detectaven i es corregien més facilment que els errors gramaticals (vegeu Nassaji 2015 per a una discussió detallada dels estudis de feedback interaccional i dels diversos factors que afecten la seva eficàcia).

\subsection{FOCUS EN LA FORMA BASAT EN TASQUES}

En l'actualitat, es reconeix àmpliament que els aprenents d'una L2, tant en el cas dels infants com en el dels adults, han de tenir un gran nombre d'oportunitats per a la interacció comunicativa. Una manera efectiva de proporcionar oportunitats a les aules de llengua és a través de tasques comunicatives, és a dir, a través d'activitats que fomentin la conversa, no per produir el llenguatge com a finalitat, sinó com un mitjà per compartir idees i opinions, colllaborant cap a un únic objectiu o competint per assolir els objectius individuals (Pica et al. 1993). És per això que des de diferents perspectives (tant des de l'àmbit de la recerca com de la didàctica) s'ha defensat l'ús de tasques comunicatives en l'adquisició i l'ensenyament d'una L2.

No obstant això, inicialment la majoria de propostes sobre l'ensenyament basat en tasques van ser purament comunicatives, és a dir, centrades més en el significat que no pas en la forma. Nunan (1989: IO), per exemple, va definir les tasques comunicatives com «un tipus de treball a l'aula que implica els aprenents en la comprensió, manipulació, producció o interacció en la llengua meta, mentre la seva atenció se centra principalment en el significat i no en la forma». Segons Ellis (1982: 75), en una tasca comunicativa «el focus de la iniciativa ha de ser en el missatge, en tot moment, i no en el canal. És a dir, els parlants han de preocupar-se del que han de dir en comptes de la manera com ho diran». Una perspectiva com aquesta és el que podem anomenar versió forta de l'ensenyament basat en tasques, que es fonamenta en el supòsit que l'aprenentatge es produeix quan l'alumnat es dedica a comunicar el significat i no quan els alumnes estan involucrats en activitats que atreuen la seva atenció cap a la forma.

La versió forta de l'ensenyament basat en tasques s'ha considerat inadequada, ja que els investigadors s'han adonat de la importància del focus en la forma. Això ha portat a buscar maneres d'incorporar un focus en la forma en les activitats basades en tasques. En l'actualitat, hi ha diverses propostes sobre la manera com es pot aconseguir un focus en la forma a les classes de llengua a partir de tasques. Com s'ha assenyalat anteriorment, Nassaji (1999) va proposar dues maneres: mitjançant els processos i mitjançant el disseny. 
L'atenció a la forma mitjançant el procés es produeix quan l'aprenent està duent a terme una tasca comunicativa no focalitzada. Les tasques no focalitzades són aquelles que estan dissenyades per tenir un focus exclusivament comunicatiu i no es fa cap esforç en el disseny de la tasca per centrar l'atenció dels aprenents sobre cap forma lingüística en particular (Ellis 2003). El focus en la forma es pot incorporar a les tasques no focalitzades per mitjà d'activitats pretasca i posttasca. Alguns exemples d'activitats pretasca inclouen la pluja d'idees, la revisió dels materials rellevants per a la tasca o les discussions sobre la formació de grups. Durant aquesta etapa, el docent també pot tractar qualsevol de les formes lingüístiques necessàries per a l'execució d'una tasca o proporcionar feedback quan s'adoni que l'aprenent comet un error durant la discussió. En aquest moment, es poden abordar tant els elements lèxics com els gramaticals necessaris per a la tasca. El focus en la forma també es pot aconseguir a través de la planificació de pretasques, és a dir, donant temps als alumnes per reflexionar i planificar la manera com duran a terme la tasca. La recerca ha suggerit que aquestes activitats tenen efectes positius sobre la correcció quan els aprenents realitzen la tasca (Ellis 2009; Skehan 2009).

Les activitats posttasca són activitats de seguiment relacionades amb la tasca que els estudiants fan després de completar-la. Alguns exemples són la preparació d'un informe escrit, la presentació dels resultats de la tasca a la classe o la discussió dels resultats amb els companys durant les discussions en grups petits. Les activitats posttasca poden oferir ocasions útils per detectar els problemes lingüístics que tenen els alumnes i proporcionar-los feedback.

El focus en la forma mitjançant el disseny es pot aconseguir per mitjà de diversos tipus de tasques focalitzades. Es tracta de tasques dissenyades de manera que algunes de les característiques lingüístiques sobresurtin en el disseny de la tasca (Ellis 2003). Un exemple d'una tasca focalitzada és la tasca gramatical. Es tracta de tasques que requereixen que els aprenents es comuniquin entre ells, però que comuniquin algun contingut de gramàtica (Nassaji \& Fotos 2004). L'objectiu d'aquestes tasques és proporcionar als aprenents l'oportunitat de reflexionar i descobrir les normes subjacents a certes estructures. Per exemple, es poden donar als aprenents targetes d'activitat amb algunes frases en les quals s'utilitzi l'estructura meta correctament $i$ algunes frases en les quals s'utilitzi la mateixa estructura de manera incorrecta. Es poden donar als aprenents frases correctes i incorrectes i després se'ls pot demanar que treballin junts per descobrir el motiu pel qual les frases són correctes o incorrectes i també descobrir les regles subjacents en les frases correctes. Diversos estudis suggereixen que aquestes tasques poden ser útils per promoure millores en el coneixement del contingut gramatical tractat i que alhora permeten mantenir el focus en el significat i, per tant, 
Hossein NASSAjI

Com integrar un focus en la gramàtica a les classes comunicatives de llengua

mantenir els beneficis de la interacció basada en tasques (Fotos 1993, 1994; Fotos \& Ellis 199I). Per tant, es poden utilitzar en les classes comunicatives com una estratègia de focus en la forma.

Un altre exemple de tasca focalitzada són les tasques de consciència metalingüistica dirigida, en les quals es demana als aprenents no només que descobreixin, sinó també que verbalitzin la raó que justifica una determinada estructura lingüística i que ho facin tot utilitzant el metallenguatge. Aquest procés de reflexió i verbalització és similar al que Swain (2006) va anomenar languaging i que defineix «com una forma de verbalització utilitzada per negociar les solucions a problemes complexos i tasques». Un exemple d'aquest tipus de tasques es pot trobar a Suzuki (20I2: III8), en un estudi en què es va demanar als estudiants que escrivissin en resposta a una consigna escrita per elicitar les estructures del passat condicional en anglès (per exemple, «Si poguessis conèixer un famós o un esportista, qui triaries i per què?»). A continuació, el docent revisava l'escrit i corregia les frases errònies dels aprenents. En una activitat de seguiment, es va demanar als aprenents que reflexionessin sobre el feedback del professorat i decidissin per quin motiu la seva forma lingüística havia estat considerada errònia $\mathrm{i}$ per què havien rebut feedback. Es va concloure que donar aquestes oportunitats als aprenents per parlar i reflexionar sobre la seva producció lingüística els ajudava en la correcció de la seva producció escrita.

Finalment, cal destacar que aquestes tasques metalingüístiques s'han de fer servir com a suport de les unitats comunicatives i que, per tant, s'han d'integrar en les activitats d'aprenentatge que tenen com a objectiu general el desenvolupament de les habilitats comunicatives.

\section{CONCLUSIÓ}

En els darrers anys, els investigadors en ASL semblen estar d'acord, en gran mesura, que l'atenció a la forma en l'aprenentatge d'L2 és crucial i, per això, han defensat els enfocaments que promouen un focus en la forma en les classes comunicatives d'L2. En aquest article, s'ha ofert, en primer lloc, una breu descripció de la base teòrica i empírica de l'enfocament del focus en la forma i després s'han revisat una sèrie d'estratègies per centrar l'atenció dels aprenents cap a les formes gramaticals en contextos comunicatius. També s'ha mencionat breument la investigació que ha avaluat l'eficàcia de cada enfocament. En general, els resultats dels estudis han estat positius, però també han indicat que els efectes de les diferents estratègies són complexos i poden variar depenent de diversos factors relacionats amb l'alumne o amb el context. Un factor 
molt important, entre d'altres, és fins a quin punt l'aprenent està a punt des del punt de vista del nivell de desenvolupament de la seva interllengua a l'hora d'aprendre un aspecte gramatical (learner's developmental readiness). Alguns estudis han mostrat, per exemple, que la instrucció gramatical és més efectiva quan va dirigida a les formes gramaticals per a les quals els aprenents estan a punt. En concret, Mackey \& Philp (1998) van mostrar que els aprenents que estaven més preparats en el seu nivell de desenvolupament es beneficiaven més de les reformulacions que no pas els que no ho estaven. Això suggereix, doncs, que quan s'utilitzen les estratègies de focus en la forma, els docents han de ser conscients d'aquests factors i han de valorar la manera d'ajustar el seu ensenyament al nivell d'interllengua i a les necessitats dels aprenents.

Ara bé, estar a punt des del punt de vista del desenvolupament de la interllengua dels aprenents no garanteix que adquireixin l'estructura de l'L2 o que la facin servir immediatament en la seva producció (Larsen-Freeman 20I5). És així perquè la preparació del desenvolupament pot estar relacionada amb altres factors, com ara el nivell de l'Li i de l'L2 per part dels aprenents. També és possible que els aprenents es beneficiïn de la instrucció fins i tot si no estan a punt des del punt de vista de la seva interllengua. L'estudi de Spada \& Lightbown (1999), per exemple, va mostrar que quan els aprenents rebien instrucció sobre preguntes en anglès, es beneficiaven de la instrucció gramatical independentment de l'estadi de desenvolupament en què es trobaven. L'aprenentatge també pot dependre molt del context i del temps que s'hi dedica. Si les condicions d'aprenentatge i el context de producció no coincideixen, pot ser que els aprenents no transfereixin l'aprenentatge als nous contextos (Lightbown 2008). L'aprenentatge és un procés gradual que requereix temps i els aprenents necessiten hores d'instrucció i exposició per usar les estructures de l'L2 de manera correcta i en la seva producció (Ellis 2008; Larsen-Freeman 20I5).

A més, tal com s'ha mencionat anteriorment, el focus en la forma es pot fer de múltiples maneres. Tot i que hi ha suport empíric a favor de la instrucció gramatical en contextos comunicatius en general, encara hi ha molta polèmica al voltant de l'efectivitat relativa dels diferents tipus d'instrucció. Per exemple, els estudis que han comparat l'ensenyament explícit i l'implícit han mostrat en general un avantatge a favor de l'explícit. Així, en la seva metaanàlisi, Norris \& Ortega (2000) van concloure que la instrucció explícita és més efectiva que la implícita. Amb tot, s’ha argumentat que la majoria dels estudis en la seva metaanàlisi van utilitzar punts gramaticals concrets no comunicatius o tests metalingüístics per mesurar el paper de la instrucció. Per això, els resultats de la metaanàlisi van ser esbiaixats a favor de la instrucció explícita (Doughty 200I).

Per acabar, voldria destacar que ja que les diferents estratègies de focus en la forma poden contribuir de manera diferent a l'aprenentatge de l'L2, la millor estratègia 
d'ensenyament és la que fa servir el focus en la forma juntament amb altres estratègies. A més, depenent del context d'ensenyament-aprenentatge, pot ser que a vegades hi hagi la necessitat de posar més èmfasi a l'aula d'L2 en activitats explícites centrades en la forma, mentre que altres vegades hi hagi més necessitat d'èmfasi en activitats comunicatives centrades en el significat. Per maximitzar l'aprenentatge, com Nassaji \& Fotos (2010: 138-139) van destacar, «els docents han de ser eclèctics en el seu enfocament instruccional»; és a dir, "per assolir l'èxit s'han de triar i sintetitzar els millors elements, els principis i les activitats dels diferents enfocaments per a l'ensenyament de la gramàtica». El currículum d'ensenyament-aprenentatge d'L2 i les pràctiques a l'aula han d'incloure components de l'ensenyament de la gramàtica, de l'ús comunicatiu del llenguatge i de les destreses d'escriptura, comprensió lectora i oral i de lectura, a partir principalment de textos o gèneres. L'eclecticisme no hauria de ser una combinació atzarosa d'estratègies, sinó que s'hauria de basar en principis sorgits a partir tant de la teoria d'ensenyament-aprenentatge de l'L2 com de la recerca, i hauria de centrar-se en les estratègies particulars sempre que es pugui, depenent del context, les necessitats dels aprenents i els objectius d'ensenyament.

Hossein NAssajI

University of Victoria, Victoria (Canadà)

nassaji@uvic.ca

\section{REFERÈNCIES BIBLIOGRÀFIQUES}

Allen, L. Q. (2000) «Form-meaning connections and the french causative: An experiment in processing instruction", Studies in Second Language Acquisition, 22, pp. 69-84.

Bastons, N., C. Bernadó \& L. Comajoan (20II). Gramàtica pràctica del català, Barcelona, Teide.

Benati, A. (200I) «A comparative study of the effects of processing instruction and output-based instruction on the acquisition of the italian future tense», Language teaching Research, 5, pp. 95-127.

Benati, A. \& J. Lee (2008) Grammar acquisition and processing instruction: Secondary and cumulative effects, Clevedon, Multilingual Matters.

Camps, A., coord. (2005) Bases per a l'ensenyament de la gramàtica, Barcelona, Graó.

Camps, A. \& M. Ferrer, coords. (2000) Gramàtica a l'aula, Barcelona, Graó. 
CARDIERNO, T. (1995) «Formal instruction from a processing perspective: An investigation into the Spanish past tense», The Modern Language Journal, 79, pp. I79-193.

Carroll, S. \& M. SWAIN (1993) «Explicit and implicit negative feedback: An empirical study of the learning of linguistic generalizations», Studies in Second Language Acquisition, I5, pp. 357-386.

Castañeda, A., coord. (20I4) Enseñanza de gramática avanzada de ELE: Criterios y recursos, Madrid, Edinumen.

Cheng, A. (2002) «The effects of processing instruction on the acquisition of ser and estan, Hispania, 85, pp. 900-909.

ComajoAn, L. (200I) «Materials d'aprenentatge de català com a llengua estrangera», dins Premi John McDowell 1999, Barcelona, Generalitat de Catalunya / Departament de Cultura, pp. I03-I79.

- (2014a) «Tendències actuals en l'ensenyament de la gramàtica en contextos de primera o segona llengua: el cas del català", Lenguaje y textos, 40, pp. 33-48.

- (20I4b) «La enseñanza de la gramática en la enseñanza-aprendizaje de lenguas: bibliografía básica», Lenguaje y textos, 40, pp. 73-78.

Consorci Per a la Normalització Lingüística (20I5), IV Jornada Aprendre Llengües al Segle XXI. [En línia: http://wiki.cpnl.cat/doku.php/4jornadaens:inici.]

Cuenca, M. J. (2005) «Teories lingüístiques i ensenyament de llengües», dins M. Solé (coord.) Metodologia de l'ensenyament de la llengua catalana, Barcelona, Universitat Oberta de Catalunya, pp. I-6I.

Dekeyser, R. \& G. Botana (20I4) «The effectiveness of processing instruction in L2 grammar acquisition: A narrative review», Applied Linguistics, 36, pp. 290-305.

DeKeyser, R. \& K. Sokalski (200I) «The differential role of comprehension and production practice», Language Learning, 5I, pp. 8I-II2.

Doughty, C. (200I) «Cognitive underpinning of focus on form», dins P. Robinson (ed.), Cognition and second language instruction, Cambridge, Cambridge University Press, pp. 206-257.

Doughty, C. \& E. Varela (I998) «Communicative focus on form», dins C. Doughty \& J. Williams (eds.), Focus on form in classroom second language acquisition, Cambridge, Cambridge University Press, pp. II4-I38.

Doughty, C. \& J. Williams (1998a) «Pedagogical choices in focus on form», dins C. Doughty \& J. Williams (eds.), Focus on form in classroom second language acquisition, Cambridge, Cambridge University Press, pp. 197-26I.

Doughty, C. \& J. Williams, eds. (1998b), Focus on form in classroom second language acquisition, Cambridge, Cambridge University Press. 
Hossein NassajI

Com integrar un focus en la gramàtica a les classes comunicatives de llengua

ElLIS, R. (1982) «Informal and formal approaches to communicative language teaching», ELT Journal, 36, pp. 73-8I.

— (200I) «Introduction: Investigating form-focused instruction», Language Learning, 5I, pp. I-46.

- (2003) Task-based language learning and teaching, Oxford, Oxford University Press.

- (2006) «Current issues in the teaching of grammar: An SLA perspective», TESOL Quarterly, 40, pp. 83-107.

— (2008 [ra ed. 1994]) «The study of second language acquisition», Oxford, Oxford University Press.

- (2009) «The differential effects of three types of task planning on the fluency, complexity, and accuracy in L2 oral production", Applied Linguistics, 30, pp. 474-509.

Fotos, S. (1993) «Consciousness-raising and noticing through focus on form-grammar task-performance versus formal instruction", Applied Linguistics, I4, pp. 385-407.

- (1994) «Integrating grammar instruction and communicative language use through grammar consciousness-raising tasks», TESOL Quarterly, 28, pp. 323-35I.

Fotos, S. \& R. ElLIS (199I) «Communicating about grammar: A task-based approach», TESOL Quarterly, 25, pp. 605-628.

Fotos, S., \& H. NassajI, eds. (2007) Form-focused instruction and teacher education: Studies in honour of Rod Ellis, Oxford, Oxford University Press.

Gass, S. (2003) «Input and interaction», dins C. Doughty \& M. Long (eds.), The handbook of second language acquisition, Oxford, Blackwell, pp. 224-255.

Harley, B. \& M. SwaIN (1984) "The interlanguage of immersion students and its implications for second language teaching», dins A. Davies, C. Criper \& A. P. R. Howatt (eds.), Interlanguage, Edimburg, Edinburgh University Press, pp. 29I-3II.

Kowal, M. \& M. SwaIn (1994) "Using collaborative language production tasks to promote students' language awareness», Language Awareness, 3, pp. 73-93.

LAPKIN, S., D. HART \& M. SWAIN (I99I) «Early and middle french immersion programs - french-language outcomes", Canadian Modern Language Review, 48, pp. II-40.

LARSEN-FreEmAN, D. (2015) «Research into practice: Grammar learning and teaching», Language Teaching, 48, pp. 263-280.

Lee, J. \& A. Benati, eds. (2013) Individual differences and processing instruction, Londres, Equinox.

Lee, J. \& B. VanPatten (1995) Making communicative language teaching happen, San Francisco, McGraw-Hill.

LeE, S. K. \& H. Huang (2008) «Visual input enhancement and grammar learning: A meta-analytic review», Studies in Second Language Acquisition, 30, pp. 307-331.

Leeman, J. (2003) «Recasts and second language development: Beyond negative evidence», Studies in Second Language Acquisition, 25, pp. 37-63. 
LI, S. (2010) "The effectiveness of corrective feedback in SLA: A meta analysis», Language Learning, 6o, pp. 309-365.

Lightbown, P. (1992) «What have we here? Some observations on the influence of instruction on L2 learning», dins R. Philipson, E. Kellerman, L. Selinker, M. Sharwood Smith \& M. Swain (eds.), Foreign language pedagogy research: A commemorative volume for Claus Faerch, Clevedon, Multilingual Matters, pp. 197-2I2.

- (1998) «The importance of timing in focus on form», dins C. Doughty \& J. Williams (eds.), Focus on form in classroom second language acquisition, Cambridge, Cambridge University Press, pp. 177-I94.

- (2008) «Transfer appropriate processing as a model for classroom second language acquisition», dins Z. Han (ed.), Understanding second language process, Bristol, Multilingual Matters, pp. 27-44.

Lightbown, P. \& N. Spada (1990) «Focus on form and corrective feedback in communicative language teaching», Studies in Second Language Acquisition, I2, pp. 429-448.

Lightbown, P. \& N. Spada (1993) How languages are learned, Oxford, Oxford University Press.

Llopis García, R., J. M. Real \& J. P. Ruiz Campillo (20I2) Qué gramática enseñar, qué gramática aprender, Madrid, Edinumen.

Loewen, S. (2015) Introduction to instructed second language acquisition, Nova York, Routledge.

LoNG, M. (I99I) «Focus on form: A design feature in language teaching methodology», dins K. DeBot, R. Ginsberge \& C. Kramsch (eds.), Foreign language research in cross-cultural perspective, Amsterdam, John Benjamins, pp. 39-52.

- (1996) "The role of the linguistic environment in second language acquisition", dins W. Ritchie \& T. Bhatia (eds.), Handbook of second language acquisition, San Diego, Academic Press, pp. 4I3-468.

- (2000) «Focus on form in task-based language teaching», dins R. D. Lambert \& E. Shohamy (eds.), Language policy and pedagogy: Essays in honor of A. Ronald Walton, Filadèlfia, John Benjamins, pp. I79-192.

LonG, M. \& P. Robinson (1998) «Focus on form: Theory, research and practice», dins C. Doughty \& J. Williams (eds.), Focus on form in classroom language acquisition, Cambridge, Cambridge University Press, pp. I5-4I.

LysteR, R. (1998) «Negotiation of form, recasts, and explicit correction in relation to error types and learner repair in immersion classrooms», Language Learning, 48, pp. 183-218.

- (2004) «Differential effects of prompts and recasts in form-focused instruction», Studies in Second Language Acquisition, 26, pp. 399-432. 
Hossein NassajI

Com integrar un focus en la gramàtica a les classes comunicatives de llengua

- (2016) "La integració de la llengua al currículum d'immersió», dins N. Camps, M. Casas, L. Comajoan \& T. Puntí (eds.), L'ensenyament del català als territoris de parla catalana, Vic, Servei de Publicacions de la Universitat de Vic, pp. I5-32.

Lyster, R. \& L. Ranta (1997) «Corrective feedback and learner uptake: Negotiation of form in communicative classrooms", Studies in Second Language Acquisition, I9, pp. 37-66.

Lyster, R. \& K. Saito (20IO) "Oral feedback in classroom SLA: A meta-analysis», Studies in Second Language Acquisition, 32, pp. 265-302.

MackeY, A. \& J. Goo (2007) «Interaction research in SLA: A meta-analysis and research synthesis», dins A. Mackey (ed.), Conversational interaction in second language acquisition: A collection of empiricalstudies, Oxford: Oxford University Press, pp. 407-452.

Mackey, A. \& J. Philp (1998) «Conversational interaction and second language development: Recasts, responses, and red herrings?», Modern Language Journal, 82, pp. 338-356.

Morgan-Short, K. \& H. W. Bowden (2006) «Processing instruction and meaningful output-based instruction: Effects on second language development», Studies in Second Language Acquisition, 28, pp. 31-65.

NABEI, T. (1996) «Dictogloss: Is it an effective language learning task?», Working Papers in Educational Linguistics, I2, pp. 59-74.

NassajI, H. (1999) «Towards integrating form-focused instruction and communicative interaction in the second language classroom: Some pedagogical possibilities», Canadian Modern Language Review, 55, pp. 385-402.

- (2007) «Elicitation and reformulation and their relationship with learner repair in dyadic interaction», Language Learning, 57, pp. 5II-548.

- (2009) «Effects of recasts and elicitations in dyadic interaction and the role of feedback explicitness", Language Learning, 59, pp. 4II-452.

- (2015) Interactional feedback dimension in instructed second language learning, Londres, Bloomsbury Publishing.

- (2016a) «Anniversary article: Interactional feedback in second language teaching and learning: A synthesis and analysis of current research», Language Teaching Research, 4, pp. I-28.

- (2016b) «Research timeline: Form-focused instruction and second language acquisition", Language Teaching Research, 49, pp. 35-62.

Nassaji, H. \& S. Fotos (2004) «Current developments in research on the teaching of grammar", Annual Review of Applied Linguistics, 24, pp. 126-I45. 
NassajI, H. \& S. Fotos (2007) "Current issues in form-focused instruction", dins S. Fotos \& H. Nassaji (eds.), Form-focused instruction and teacher education: Studies in honour of Rod Ellis, Oxford, Oxford University Press, pp. 7-I5.

NassajI, H. \& S. Fotos (2010) Teaching grammar in second language classrooms: Integrating form-focused instruction in communicative context, Londres, Routledge.

Nassaji, H., \& Simard, D. (20IO) «Current developments in form-focused interaction and L2 acquisition", Special issue of Canadian Modern Language Review, 66, pp. 773-338.

NAsSaJI, H. \& J. Tian (20I0) «Collaborative and individual output tasks and their effects on learning English phrasal verbs», Language Teaching Research, I4, pp. 397-419.

Norris, J. M. \& L. Ortega (2000) «Effectiveness of L2 instruction: A research synthesis and quantitative meta-analysis", Language Learning, 50, pp. 417-528.

Norris, J. M. \& L. Ortega (200I) «Does type of instruction make a difference? Substantive findings from a meta-analytic review», Language Learning, 5I, pp. 157-213.

Nunan, D. (1989) Designing tasks for the communicative classroom, Cambridge, Cambridge University Press.

Oliver, R. (1995) «Negative feedback in child ns-nns conversation», Studies in Second Language Acquisition, I7, pp. 459-48I.

Ribas, T., X. Fontich \& O. Guasch (20I4) Grammar at school: Research on metalinguistic activity in language education, Brussel-les, Peter Lang.

Rodríguez Gonzalo, C \& M. J. García Folgado, coords. (20I4) La enseñanza de la gramática: pasado, presente y futuro. Monogràfic de la revista Lenguaje y textos, $4 \mathrm{O}$.

Russell, J. \& N. Spada (2006) "The effectiveness of corrective feedback for second language acquisition: A meta-analysis of the research", dins J. Norris \& L. Ortega (eds.), Synthesizing research on language learning and teaching, Amsterdam, John Benjamins, pp. I3I-I 64 .

Schmidt, R. (1990) «The role of consciousness in second language learning», Applied Linguistics, II, pp. I29-I58.

— (2010, desembre 2-4) «Attention, awareness, and individual differences in language learning» [Paper presented at the CLaSIC Singapore.]

Sharwood Smith, M. (1993) "Input enhancement in instructed SLA: Theoretical bases", Studies in Second Language Acquisition, I5, pp. I65-179.

SHEen, R. (2002) "Focus on form' and 'focus on forms'", ELT Journal, 56, pp. 303-304. SKEHAN, P. (2009) «Modelling second language performance: Integrating complexity, accuracy, fluency, and lexis», Applied Linguistics, 30, pp. 510-532. 
Hossein NassajI

Com integrar un focus en la gramàtica a les classes comunicatives de llengua

SUZUKI, W. (20I2) «Written languaging, direct correction, and second language writing revision", Language Learning, 62, pp. IIIO-II33.

SwaIn, M. (1985) «Communicative competence: Some rules of comprehensible input and comprehensible output in its development», dins S. Gass \& C. Madden (eds.), Input in second language acquisition, Rowley, Newbury House, pp. 235-253.

- (1995) "Three functions of output in second language learning», dins H. G. Widdowson, G. Cook \& B. Seidlhofer (eds.), Principle and practice in applied linguistics: Studies in honour of H. G. Widdowson, Oxford, Oxford University Press, pp. I25-I44.

- (2000) «The output hypothesis and beyond: Mediating acquisition through collaborative dialogue", dins J. P. Lantolf (ed.), Sociocultural theory and second language learning, Oxford, Oxford University Press, pp. 97-II4.

- (2006). «Languaging, agency and collaboration in advanced language proficiency», dins H. Byrnes (ed.), Advanced language learning: The contribution of Halliday and Vygotsky, Londres, Continuum, pp. 95-108.

Swain, M. \& S. Lapkin (1989) "Canadian immersion and adult second language teaching: What's the connection", The Modern Language Journal, 73, pp. I50-159.

SwaIN, M. \& S. LAPKIN (20OI) «Focus on form through collaborative dialogue: Exploring task effects», dins M. Bygate, P. Skehan \& M. Swain (eds.), Researching pedagogic tasks: Second language learning, teaching and testing, Harlow, Pearson Education, pp. 99-II8.

VanPatten, B. (1996) Input processing and grammar instruction in second language acquisition, Norwood, Ablex Pub.

- (2002) «Processing instruction: An update», Language Learning, 52, pp. 755-803.

- (2004) «Input processing in second language acquisition», dins B. VanPatten (ed.), Processing instruction: Theory, research, and commentary, Mahwah, Lawrence Erlbaum, pp. 5-31.

VanPatten, B. \& T. Cadierno (1993) «Explicit instruction and input processing», Studies in Second Language Acquisition, I5, pp. 225-244.

VanPatten, B., M. Leeser \& G. Keating (20II) Soly viento: Beginning Spanish, Nova York, McGraw-Hill.

Wajnryb, R. (1990) Grammar dictation, Oxford, Oxford University Press.

Williams, J. (2005) «Form-focused instruction», dins E. Hinkel (ed.), Handbook on research in second language teaching and learning, Mahwah, Lawrence Erlbaum, pp. 673-691.

WonG, W. (2004) «The nature of processing instruction», dins B. VanPatten (ed.), Processing instruction: Theory, research, and commentary, Mahwah, Lawrence Erlbaum, pp. 33-63. 